\title{
Influence: The Impact of Language, Credibility and Gender (version V)
}

Jane Henderson

\section{Keywords}

Persuasion, expertise, influence, gender, credibility, communication, language.

\begin{abstract}
Psychology and communication studies can help conservators to examine the impact of gender, the expectations of others and the components of credibility. A small selections of theories from psychology are used to analyse the way that people expect others to communicate and the impact on situations where expectations are breached.

The research suggests that conservators can improve their persuasiveness by increasing their understanding of the views of those that they try to influence. In addition the conservator can critically assess their own behaviour and consider if it is likely to have a positive or negative outcome.
\end{abstract}

Being aware of some of the issues that affect persuasiveness allows the conservator to analyse puzzling responses and gives them the opportunity, if they choose it, to adapt their image or style.

\section{Introduction}

Conservators can learn the skills of persuasion, just as they can study any other aspect of their work (Henderson 2001). This paper concentrates on a selection of theories that can help to explain the relationship between expertise, gender and persuasiveness. It should be noted at the outset that persuasion is situational. This means that lessons from any experience can be interpreted but not copied from one situation to another. It is not possible to draw up a simple list of 'ten top tips' for persuasiveness, as what works for one person in one situation will not necessarily work for another elsewhere. Indeed copying the apparently persuasive behaviour of a colleague can sometimes be counter-productive. Conservators who wish to increase their persuasiveness should learn to analyse encounters and identify the factors that affect their success.

Persuasion is bound up with communication. Communication science is a vast topic that has been studied in great detail. It is impossible here to cover all communication theories in any meaningful way. Accordingly the focus of this paper is on some theories that may not be familiar to most conservators, rather than to précis work from standard management texts. Readers who wish to study this topic further may find the Cialdini book Influence Science and Practice (2001) an enjoyable and comprehensive summary of some key points.

A fuller discussion on the meaning of the terms and the relationship between 'source', 'message' and 'receivers' is reported elsewhere (Henderson 2001). To summarise, persuasion research suggests that each element of a persuasive encounter: the source, (e.g. the conservator) the message, (e.g. control light levels), the receiver (e.g. the designer) and the context (e.g. a planning meeting), will have a bearing on the likely 
outcome of the persuasive attempt. A change in any one of these elements can affect the chances of successful persuasion. Persuasion involves verbal and non-verbal cues and is as varied and complex as any other communication process. In order to provide focus this paper concentrates on factors related to the source, in particular their language and gender and how they relate to each other in terms of a person's credibility and influence. Understanding the mechanisms of a situation does not necessarily resolve it but it does allow the conservator to adjust their behaviour in a constructive way (Tannen 1995:126), should they choose to do so.

Persuasion can be defined as an attempt to change the actions, beliefs or behaviours of another person. This can be on a single occasion or over a period of time.

Conservators are usually involved in many on-going persuasive encounters with their colleagues as part of their day to day work and additional, more challenging persuasive encounters when they are involved in projects such as construction and refurbishment. In such projects, conservators may find that they need to persuade unfamiliar groups of people, to carry out actions which they find unusual or difficult. An example of this would be working with contractors to minimise dust transmission during a refurbishment. Many conservators are not in senior positions in their organisations and cannot simply insist on their instructions being followed. Instead they must persuade others to comply with their requests.

\section{What makes you Persuasive?}

Source characteristics -the persuader's personality traits- are a powerful element of the persuasion package. For example, a great deal of investment is made into paying celebrities to recommend products as they can be influential sources. Alternatively politicians will seek detailed advice on their image in order to increase their influence. Conservators wishing to be persuasive can only rarely turn to celebrities to transmit their messages, and it is unlikely that they would have the resources to employ image consultants. However understanding the elements of source characteristics that affect persuasiveness means they can adapt their message, image or behaviour. A common approach is to increase the power of a message by externalising the source for example by arguing 'carrying out this action is a requirement of HLF'. At the simplest level having an awareness of how the characteristics of a source affect the persuasive encounter should improve a conservator's ability to analyse the responses that they receive.

\section{The role of Credibility}

Source credibility can be decisive when a receiver is not giving full attention to a message (Petty \& Cacioppo 1986; Reardon 1991:75-79). In this instance snap decisions can be made based on simple triggers, such as 'is the message source a credible person?' If so, the receiver may accept what they hear without taking time to analyse the arguments in detail.

So what is credibility? O'Keefe (2002:182) observes that expertise and trustworthiness are consistently described as elements of credibility. In different situations either of these factors could be more significant. The evaluation of trustworthiness will be affected by the receiver's perception of persuader self interest (Johnston 1994:151). However, people may find an untrustworthy person credible, 
and therefore persuasive in particular situations. For example, the police may be persuaded about events by a criminal informer who is evaluated as untrustworthy in general but as an expert on the subject of stolen goods. Other elements of credibility such as attractiveness (Perloff 2003:170), charisma, (Johnston 1994:153) or dynamism and sociability (Miller 1987:465) are also important and some conservators may choose to try to adapt their behaviour in these areas to increase credibility.

Credibility is not a fixed characteristic of the source but, like much of persuasion, is bound up with the other elements in the encounter (Reardon 1991). Credibility is defined when the receiver combines their assessment of themselves with their assessment of the source;

'a source's acceptability as a source of information and opinion in a given message situation is determined by a series of self source comparisons on specific judgmental decisions (e.g. one's own perceived level of knowledge about the particular issue (self competence) versus the communicators perceived level of knowledge about the particular issue (source competence)). To the extent that the receiver rates the source as higher than self on these dimensions - whatever his absolute rating- he will tend to accept the proffered influence... Thus, a source's credibility and subsequent influence potential are seen to depend not on his absolute rating, but on his evaluative standing relative to receiver self evaluation."

(Miller 1987:465-466)

A persuader may therefore have subject specific credibility in any situation, and should consider when and on what subjects they would be rated as credible (Miller 1987). A conservator in a meeting may find that they are considered credible (and therefore influential) on the topic of humidity specification, but in the same meeting may not be rated as credible on the subject of dust control. The lesson for conservators trying to influence another person is to try to establish where they fit on their target's evaluation of the relationship between self: source: subject.

\subsection{Credibility and Language Choice}

Despite the fact that a decisive element of persuasion is your target's evaluation of your credibility which can be established before you even say a word, what you do say still matters. Your influence techniques, such as choice of language and argument style can be added to the picture as factors that will influence the success, or other wise of your persuasive attempts.

\subsubsection{Language Expectancy Theory}

Language Expectancy Theory considers the relationship between the credibility of the source in the eyes of the receiver, and the language that the source uses. The theory originates from the idea that 'language is a rule-governed system' and people have social expectations and preferences about how others should communicate (Burgoon 1995). As these preferences are based on societal standards there is a tendency for individuals or groups of people to generate predictions of what is 'normal' communication behaviour for other groups of people. The theory is that 'listeners develop expectation about the language persuaders should use' (Hosman 2002). These expectations are described as 'normative' types of behaviour and once they are 
established in a receiver's mind, a persuader can positively or negatively violate these norms by communicating "better" or "worse" than had been expected (Burgoon 1995:33-35).

Research shows that there is a relationship between expectation violation and persuasiveness. A person who communicates within the levels of expectation is persuasive, and a person who positively exceeds expectations, is very persuasive, see Figure 1. Malcolm X was reported to be very persuasive because, in contrast to listener's expectations, he was well spoken and articulate. Negative violations can have the direct counter-effect of persuading the receiver to act in the opposite way to the persuader's intention. A source that use has poor communication (in comparison with what was expected) will experience an increase in non compliance with their requests (Burgoon et al 2002).

Burgoon (1995) argues that different types of people generate different expectations. It is here that gender plays a distinctive role. Women are often initially perceived as low credible communicators and as such have a much more limited range of acceptable argument strategies. In effect, the band of 'normative communication' shown on Fig 1 is narrower for women than for men. As a result the use of negative arguments by a female source will often negatively violate expectations. However, men and 'high credible sources could use either aggressive or unaggressive verbal strategies and be persuasive' (Burgoon 1995:35). As a result women are much more limited in their choice of strategies than men. Burgoon (1995:44) concludes that 'It is very difficult for a female to positively violate expectations'. The consequences of this research should be to encourage anyone who might be perceived as low in credibility on a given topic to consider using persuasive appeals which are low in verbal aggression (Burgoon, 1985:218).

\subsubsection{Verbal aggression}

A definition of verbal aggression is useful at this point. Aggression in persuasive language is defined as using negative or punishment orientated arguments. These are arguments such as 'you will feel bad if you do not do...' or to imply that 'only a bad person would not reduce light levels'. Aggressiveness in language is distinct from argumentativeness although the two issues can be confused. An argumentative individual identifies controversial issues, advocates a position on them, argues against others' opinions, speaks frequently, puts several arguments and disputes counter arguments (Miller et al 1987), they are not however necessarily verbally aggressive. Someone with high verbal aggression and low argumentativeness may use only a few negative arguments, such as repeating a single threat. This type of argument will be interpreted as being very hostile. A person with low verbal aggression and high argumentativeness may seem to be very rational and persistent (Miller et al 1987). So a conservator who simply repeats negative phrases such as 'the collections will be damaged by these lights' creates an impression of high aggression. A better strategy would be to reduce aggression whilst increasing argumentativeness by for example, using a range of different positively framed arguments.

\subsubsection{Gender and Language Expectancy Theory}

Unfortunately this research suggests that gender specific expectations exist in at least some cases and that men and women may have to use different communication techniques to achieve the same end. This description of gender bound expectations is 
also developed in much of what might be described as feminist literature (Tannen 1995:119). The research suggests that a female conservator should not be surprised to find that people pay attention to and act on a message from a male colleague having ignored exactly the same message from them. In addition it is possible that female conservators who adopt the successful verbal style of a male colleague would find that it is ineffective or even counter productive (Tannen 1995:122-134). However the principle will also operate in reverse, so male conservators should try to assess their expertise rating before choosing an argument style rather than emulating a colleague or manager. The exception to this rule applies to 'experts'. Where a person is evaluated by others as an expert they can range through an entire range of positive and negative argument strategies without negatively violating expectations. In other words a female conservator who is perceived as an expert can use the same range of argument strategies as a male colleague effectively.

\section{Compliance Gaining in High 'Other Benefit' Situations}

Some persuasion goals can be described as having 'other benefit' (Boster 1995). This occurs where the persuader believes compliance with their requests will not benefit themselves but will generate a benefit for another person or cause. The concept would apply to persuasive encounters within collections care where the conservator sees either the collections or future visitors as potential beneficiaries of their efforts.

In high 'other benefit' situations the persuader has a tendency to be 'more aggressive and persistent in their compliance-gaining attempts' (Boster 1995). Because they see the end result of their efforts as positive for the receiver or 'society in general' the conservator is likely to use stronger and stronger measures to try to achieve their goals. Although this may be effective in some cases, it will always have negative consequences. The receiver may find the experience condescending, so that despite the fact that compliance is in their best interest, they will resent the experience, and this may damage any long term relationship (Boster 1995). The perception of 'high other benefit' allows the persuader:

'to justify, to oneself and others, extremely persistent and punitive message behaviour and perhaps later action [and] to convince oneself, others, or both of the righteousness of inhuman behaviour.' (Boster 1995:103)

Whilst the widespread use of torture in museums is not anticipated, the result can be that the conservator uses very aggressive persuasive tactics and language. In the light of the conclusions from Language Expectancy Theory this could result in the target carrying out the opposite action to that advocated. In addition, the more the persuader anticipates resistance from the receiver, the more likely they are to use verbally aggressive strategies (Burgoon 1995:40). A female conservator may wish to adopt a less verbally aggressive persuasive style to increase their chance of successful persuasion.

The danger for conservators is that they can ignore their own very poor persuasive technique because they are convinced of the general benefit of their message. The resulting lack of compliance from those they try to influence is responded to only by escalating the already destructive persuasive techniques. The conservator can blind themselves of the problem because they are sure they are right. Conservators could 
train themselves to identify if they are engaged in such a negative and downward spiral which is only likely to harden the negative responses of their target.

\section{Personality Factors}

There is considerable research to show that people prefer to comply with individuals that they know and like. Researchers list physical attractiveness, similarity (Cialdini 2001:148-151) and social desirability (Steinfatt 1995:67) as some of the personality factors that impact on the persuasiveness of a message. Whilst individuals may not wish to change their personality to increase persuasiveness they should at least be aware of the issues in case they can identify elements of their behaviour that they are comfortable with adapting.

\subsection{Similarity}

Studies show that a source will be more persuasive if they are similar to their target. Similarity can be defined in terms of experience, background, attitudes and morality (Perloff 2003:169-170). Similarity has the most impact when the similarity is relevant to the persuasive event. Perlof (2003:169) suggests that when the issues being considered have a large emotional element, similarity will have a big impact, but when the issues are based in logic and facts people prefer to listen to the advice of an 'expert' who may be dissimilar. Knowing whether a similar or an 'expert' approach will be most effective is difficult, but Perloff suggests that for long term relationships, similarity will be more influential over time than expertise. When trying to be influential, conservators may try to establish areas of common experience or belief with their targets to increase their persuasiveness.

\subsection{Attractiveness}

Perloff (2003:170-171) argues that attractive people are more self confident and that attractiveness is a positive quality that can transfer its positive association onto the influence topic. In addition he suggests that people are more likely to pay attention to attractive people and that people will also identify more easily with an attractive person, so finding it easier to like them.

\subsection{Liking}

People tend to like other people who conform to similar values or norms as themselves. When people behave in a way that conforms with another's values they tend to praise that behaviour which increases liking between the parties (Rhoads \& Cialdini, 2001). Increased familiarity through repeated contact with a person will also facilitate liking if the contact is experienced in a positive atmosphere. In particular cooperation that leads to successful outcomes will increase liking and by implication should increase persuasiveness (Cialdini 2001:159). Conservators may find that participation in a successful project should increase their influence in subsequent projects with the same members.

\subsection{Impact of personality factors on influence}

When considering the influence of personality variables in the outcome of a persuasive occasion, counter factors could be considered. Hayes (1993:104) argues that if a person chooses to listen to an argument put by an unattractive person, they may try to rationalise the experience of listening to the message and end up being more persuaded in order to reduce cognitive dissonance. In simple terms, they 
mentally justify any uncomfortable feeling which arises from listening to the argument by convincing themselves it was a worthwhile thing to put up with. Reardon (1991:94) suggests, as a rule of thumb, that in a formal context where clear social rules exist, personality factors will have less influence on persuasiveness than in informal encounters.

\section{Gender}

A conservator entering a construction related project meeting representing their museum may be concerned that they will not be taken seriously and their authority as client representative is not recognised. Where the conservator is female and all the others in the room are male that sensation may be heightened. This raises the question of the impact of gender in persuasion terms.

There are many structural barriers to women achieving success, including sexual harassment, child rearing, and discrimination in promotion (Miller 1999). These will all have an effect on the degree of influence of women in work. A number of persuasion theories refer to how differences in gender affect influence (see listings in Allen et al 1993 and Giles \& Street 1994), although many concentrate on the question of whether women are more easily persuadable than men (Perloff, 2003:263). Again the topic is vast.

\subsection{Gender and Language in Compliance Gaining Attempts}

To concentrate on the issues already under discussion it is possible to focus on the relationship between the language, credibility and gender when seeking influence.

Burgoon (1995:43) argues that because of social expectations, many women are restricted in the kinds of arguments that will be effective. Reardon (1991:91) adds that:

\section{'A woman may be extremely competent and have strong evidence supporting her case and still fail to persuade merely because her language or actions suggest low power and influence to those with whom she is communicating.'}

This applies in particular where a woman offers an opinion on what might be considered a 'masculine' topic (Reardon 1991:88). The persuasive effectiveness of a female source will therefore be shaped by the reactions of the receiver (Steckler \& Rosenthal 1985). Research shows that there are 'no actual differences between men and women ['s behaviour] that can account for differences in organisational experiences' (Miller 1999:239). It is possible to conclude from this that women cannot expect to behave similarly to men in their workplace and achieve the same results.

It may however be the case that as social expectations change so will the status of women. Research conducted in America amongst college students in 1989 on the persuasiveness of various sources found no bias amongst the students for gender (Reardon 1991:91). This may be an indication that attitudes are changing and that gender differences will become less significant over time (Weber 1994, Perloff 2003: 263). It is worth noting that it is impossible to make definitive statements about the 
experience of all women, as the experience of discrimination, or success, will be affected by other factors (Arth 1994:97). There is also some research that suggests that just as women are seen as less credible by some sources, by others they are perceived as more credible. It is therefore possible that as differences diminish so do some advantages (Steckler \& Rosenthal 1985).

Women who wish to overcome any initial low credibility assessment may choose to counteract this by conforming strictly to organisational rules, increasing the use of rationality when influencing bureaucrats and strangers and using whatever 'masculine' influence behaviours that bring status to male colleagues (Cody \& McLaughlin 1990, Steckler \& Rosenthal 1985). However, in addition to the potential dangers of copying masculine verbal communication, imitating masculine behaviour has also been reported as being counter productive for women (Tannen 1995: 122).

\subsection{Systematic Barriers for Women}

Looking beyond verbal communication, one description of the systematic barriers to women in organisations identifies four particular problem areas for women:

- exclusion from informal communication networks

- lack of mentor-protégé relationships

- tokenism, and

- limited areas of work opportunities

(Miller 1999:240)

In persuasion terms the lack of access to informal networks is the most significant, but each area illustrates how a female conservator may loose out on an opportunity to increase her influence. By missing out on the social, work, and supportive contact that a male colleague may have, a woman is less likely to understand and accurately interpret the beliefs and values held by male colleagues. She may also be excluded from the benefits of the positive associations of humour, food (or beer) if excluded from social circles (Pfau \& Parrott 1993, Petty et al. 1981). If limitations exist on the type of work that a woman can undertake when she starts in an organisation, her areas of expertise may be different from the senior managers who consider that their expertise is the appropriate knowledge for a decision maker. So a conservator rising through the ranks may experience credibility problems with other managers who see curatorial backgrounds as a more appropriate starting point for a career in museum management.

The conservation profession has many successful female role models and in these circumstances it is easy to think that gender discrimination is not significant, especially if your manager is a woman. However conservation does not exist in isolation and discrimination remains a feature of working life in the UK. To cite just one example, the average hourly pay for women in the UK remains only $81.8 \%$ of men's (Office for National Statistics, 2004).

\section{Practical applications}

This article has examined some of the factors that determine the persuasiveness of a source. In order to illustrate these theories in practice, two scenarios are suggested which answer the tricky questions; 'Why do some of our colleagues not like conservators?' and 'How can I be more credible?' 


\subsection{Why do some of our colleagues not like conservators? \\ 'Certainly, many remarks made on the questionnaires suggests very poor attitudes to conservation on the part of some museum directors and curators. Conservators often felt that they are tolerated but regarded as a nuisance.' (Corfield et al, 1987:26)}

Some conservators consider their role to be unique (Ashley-Smith, 1990:16) and because of that, project an image of themselves as a distinct group in their organisation, portraying themselves as the sole guardians of the collections. If the experience of working with conservators leaves others in the museum with the experience of them being 'negative spoil sports' (Keene, 1996:112) this will decrease similarity, liking and therefore respect. Conservators who wish to be valued should stress that they have common aims with their colleagues (Bradley, 1990:25).

Conservators may not wish to manipulate their entire personality to achieve persuasiveness, but small changes may be acceptable, for example by considering what you wear. Whilst many people in museums wear suits or smart clothes the conservators may dress in lab coats or overalls. Cane (1999:66) commented that a difference in work clothes can be taken as a symbolic representation of a difference in attitudes. The practicalities of laboratory work may make a change in everyday clothes impractical or even undesirable. However, occasions may arise where dressing in a similar way to others, for example wearing a suit to a meeting may reduce the chance of people questioning your authority and expertise.

Similarity should also be sought on issues relevant to the persuasive topic. A conservator who wanted to argue that staff wear gloves when moving furniture should first establish an agreement with the relevant staff on the quality of the surface finishes and therefore establish a similar view of the value of the furniture, before launching into the reasons for wearing gloves. Another way to increase liking is by giving praise (generating satisfaction) although this has to be in proportion to the situation to be convincing (Cialdini, 2001:152).

\subsection{How can I get more credibility? \\ 'Conservators are highly knowledgeable and intelligent...The trouble is conservators lack credibility,' (Keene, 1996:113)}

Where a conservator knows that their target does not perceive them as an expert because of their status or gender, they should consider the relevance of language expectancy theory, and high 'other benefit' compliance as keys to success. To illustrate this, consider the scenario where a younger female conservator is trying to persuade an older male curator to change the way exhibitions are organised to include consulting conservators at every stage of the project. The curator sees this as his area of expertise as he has been organising exhibitions for years. He may have clearly defined priorities such as, to finish on time, on budget and to cover three key stages of the National Curriculum. The conservator's priority in this scenario is to change the way that new exhibitions are planned, and she predicts that the outcome of her suggestions would be extremely beneficial for other people and the collections. 
In arguing her case the conservator strays from the 'normative band' band of communication and uses negative arguments such as, 'the collections will be damaged by these terrible lights' and 'only unprofessional curators don't operate in the way I suggest'. The conservator considers the subject as her own area of expertise and is confident that her suggestions will generate the best outcome for the collections. Confident that she is in the right the conservator persists in her argument technique and in the face of failure escalates the strength of the negative arguments. Meanwhile the curator feels more and more antagonised by the procedure and at each escalation becomes more determined to resist, finally resorting to avoiding the conservator by excluding them from discussions or by using their greater absolute power in the organisation to by-pass their concerns. This 'Boomerang' effect of creating change opposite to the position advocated by the persuader (Burgoon et al, 2004:122) may be a familiar experience to some conservators.

A better approach in this scenario would have been to identify the curator's perceptions of the situation and adapt accordingly. The conservator should make positive initial suggestions such as offering to help the curator to produce text on conservation that ties to a key stage of the National Curriculum. They may be able to identify savings that could be made with more efficient lights and make other positive contributions before they introduce some of the more complex requirements. In this situation the approach of making small starting requests and then ratcheting up the demands would be most effective (Cialdini, 2001:53-96), whilst verbally protecting the curator's ego with positive reward centred arguments.

\section{Conclusion}

This brief review has identified how communicating to persuade others is a complex activity which involves much more than oral skills and expert language. Who we are, our backgrounds and gender will have a significant role in how we are perceived by others and this should inform the strategies we use to convince and convert. The conservator's love affair with their objects (Drysdale 1988) should not blind them to the need to constantly review their image and response to people.

Conservators should recognise that the status, credibility and personality of a persuader are all significant variables in the persuasion process. The impact that they have will always be governed by circumstances. Conservators may like to think that those around them always make decisions based on the quality of their arguments, sadly this is not the case. An awareness of some of the other issues that might be taken into account will allow the conservator to analyse puzzling responses and give them the opportunity, if they choose it, to adapt their image or style. 
Figure1 A Model for Language Expectancy Theory

The interaction between expected behaviour, enacted behaviour and persuasiveness

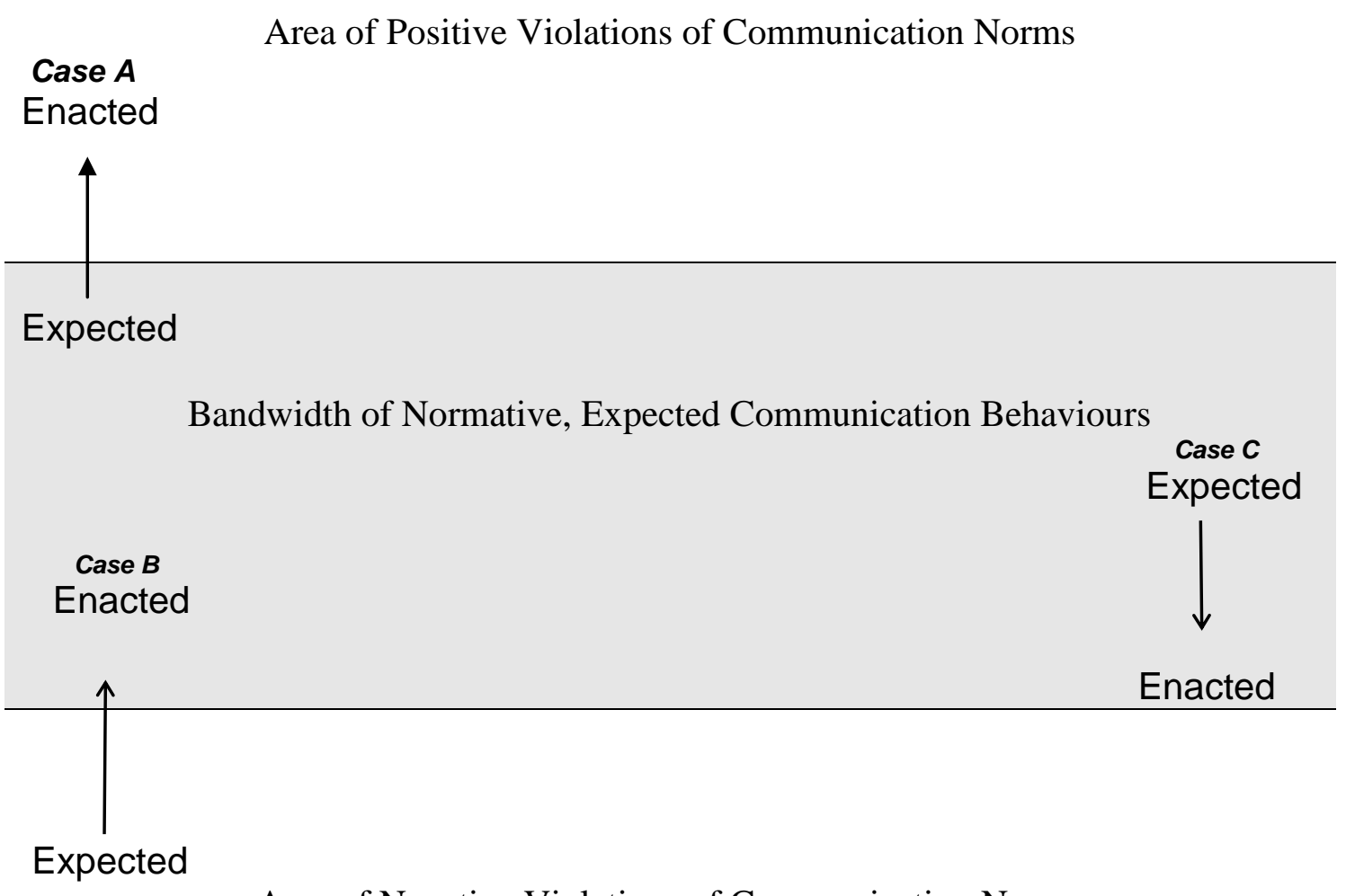

Area of Negative Violations of Communication Norms

Case A: Positive violation of expectations.

Initial expectation of behaviour is that the communicator would perform within normal parameters. The communication exceeded initial expectations. It is likely to result in a change in attitude or behaviour in line with that which is advocated by the communicator.

Case B: Positive violation of expectations.

Initial expectations of behaviour were that the communicator would have poor communication. The actual communication was better than expected and fell within what might be considered the 'normal' type of communication for that kind of person. It is likely to result in a change in attitude or behaviour in line with that which is advocated by the communicator.

Case C: Negative violation of expectations.

Initial expectations of behaviour were that the communicator would perform within normal parameters. The actual communication was worse than expected. It is likely to result in a change in attitude or behaviour in the opposite direction than that which is advocated by the communicator.

Adapted from Burgoon, 1995:31. 


\section{References}

Allen, M. W. Gotcher, J. M. \& Seibert, J. H. 1993 A Decade of Organizational Research: Journal Articles 1980-1991, In: Deetz, S. A (ed.) Communication Yearbook 16. International Communication Association Sage Publications, California USA, 252-330.

Arth, M. 1994 Interpreting Gender Perspectives, In: Glaser \& Zenetou (eds.) Gender Perspectives; Essays on Women in Museums Smithsonian Institute Press, Washington USA, 28-31.

Ashley-Smith, J. 1990: Managing Conservators, In: Keene (Ed.) Managing Conservation UKIC, London, 16-20.

Boster, F. J. 1995 Commentary on Compliance gaining message behaviour research, In Berger \& Burgoon (eds) Communication and Social Influence Processes, Michigan State University Press, USA 91-114.

Bradley, S. 1990 Do Objects Have a Finite Life? in Keene (Ed.) Managing Conservation UKIC, London, 24-27.

Burgoon, M., Denning, V., P. \& Roberts, L A. 2002 Language and Persuasion in Dillard, J.P. \& Pfau, M. The Persuasion Handbook Developments in Theory and Practice Sage Publications, California, USA 117-136

Burgoon, M. 1995 Language expectancy theory: Elaboration, Explication and Extension, In: Berger, C R \& Burgoon, M (eds) Communication and Social Influence Processes Michigan State University USA, 29-51.

Burgoon, M. \& Miller G. R 1985 An expectancy Interpretation of language and persuasion, In Giles, H \& St Claire, R, (eds) Recent Advances in Language Communication and Social Psychology Lawrence Erlbaum, London UK, 199-229.

Cane, S. 1999 Oily Rags or Cotton Buds? in Dollery, D \& Henderson, J. (eds.) Industrial Collections: Care and Conservation UKIC \& CMW, London UK, 65-71

Cialdini, R.B. 2001 Influence: Science and Practice 4th Edition Harper Collins, New York USA.

Cody, M. J. \& McLaughlin, M. L. 1990 Introduction, In: Cody, M. J. \& McLaughlin, M. L. (eds.) The Psychology of Tactical Communication Multilingual Matters Ltd, Clevedon England, 1-28.

Corfield M., Keene, S. \& Hackney, S. 1987 The Survey: Conservation Facilities in Museums \& Galleries United Kingdom Institute for Conservation, London 26.

Drysdale, L. 1988 The eternal triangle: Relationships between conservators their clients and objects. In Todd, V.(Ed.) Conservation Today. Pre-prints for the UKIC $3^{\text {th }}$ Anniversary Conference UKIC, London pp 18-20. 
Giles, H. \& Street, R. L. 1994 Communication Characteristics and Behavior, In Knapp \& Miller (eds.) Handbook of Interpersonal Communication 2nd Edition Sage Publications, California USA, 103-161.

Hayes, N. 1993 Principles of Social Psychology A Volume in the Series Principles of Psychology, Lawrence Erlbaum Associates, Hillsdale, USA.

Henderson, J. 2001 New Skills New Influence in Oddy, A \& Smith S (eds), Past Practice - Future Prospects The British Museum Occasional Paper Number 145 pp.103-108

Hosman, L. A. 2002 Language and Persuasion in Dillard, J.P. \& Pfau, M. The Persuasion Handbook Developments in Theory and Practice Sage Publications, California, USA 384

Johnston, D. 1994 The art and science of persuasion: Madison, Wisconsin: Brown \& Benchmark publishers.

Keene, S. 1996 Managing Conservation in Museums Butterworth-Heinemann and The Science Museum, Oxford UK 112.

O'Keefe, D. J. 2002 Persuasion Theory and Research $2^{\text {nd }}$ Edition Sage

Publications, California USA.

Miller, G. R. 1987 Persuasion, In Berger \& Chafee (eds) Handbook of

Communication Science Sage Publications, California USA 446-483.

Miller, G. R., Boster, F. J., Roloff, M. E. \& Seibold, D. R. 1987 MBRS Rekindled, Some Thoughts on Compliance Gaining in Interpersonal Settings, In: Roloff, M. E. \& Miller, G. R. (eds.) Interpersonal Communication Sage Publications, California USA, 89-116.

Miller, K. 1999 Organizational Communication: Approaches and Processes 2nd edition, Wadsworth USA

Office for National Statistics, 2004 Annual Survey of Hours and Earnings National Statistics Online, www.statistics.gov.uk UK

Perloff, R. M. 2003 The Dynamics of Persuasion Communication and Attitudes in the 21st Century $2^{\text {nd }}$ edition Lawrence Erlbaum Associates, Hillsdale, New Jersey USA.

Petty, R., E Cacioppo, J. T. \& Goldman, R. 1981 Personal Involvement as a Determinant of Argument - Based Persuasion Journal of Personality and Social Psychology Vol. 42. No 5. 847-855.

Petty, R. E. \& Cacioppo, J. T. 1986 The Elaboration Likelihood Model of Persuasion, In Berkowitz, L. (ed.) Advances in Experimental Social Psychology Volume 19 Academic Press Inc. USA 123-192. 
Pfau, M. \& Parrott, R. 1993 Persuasive Communication Campaigns Allyn and Bacon, Boston USA.

Reardon, K. K. 1991 Persuasion in Practice Sage Publications, Newbury Park USA.

Rhoads, K. v. L. \& Cialdini, R. B. 2002 The Business of Influence: Principles that Lead to Success in Commercial Settings in Dillard, J.P. \& Pfau, M. The Persuasion Handbook Developments in Theory and Practice Sage Publications, California, USA 533)

Steckler, N. A. \& Rosenthal, R. 1985 Sex Differences in Nonverbal and Verbal Communication With Bosses, Peers, and Subordinates, Journal of Applied Psychology The American Psychological Association Inc. 157-163.

Steinfatt, T. M. 1995 Communication and Personality: Improving the Predictive Fit, In: Berger, C.R. \& Burgoon, M (eds.) Communication and Social Influence Processes, Michigan State University Press, 53-67.

Tannen, D. 1995 Talking From 9 to 5: How Women's and Men's Conversational Styles Affect Who Gets Heard, Who Gets Credit and What Gets Done at Work Virago Press London UK.

Weber, J. 1994 Changing Roles and Attitudes, In: Glaser \& Zenetou (eds.) Gender Perspectives; Essays on Women in Museums, Smithsonian Institute Press, Washington USA 28-31.

\section{Biography}

Jane Henderson AMUKIC, FIIC has been working in and studying in conservation and collections care in Wales since 1984. She has a BSc in Archaeological Conservation and an MSc in Collections Care. Jane has worked in conservation in both the public and private sectors including acting as Conservation Manager for the Council of Museums in Wales. Jane now teaches on Cardiff University's BSc in Conservation and MSc in Collections Care. Jane continues to offer consultancy services in collections care. Recent projects include a report into the state of archaeological archives in Wales and a storage assessment for the National Maritime Museum.

Email hendersonLJ@Cardiff.ac.uk or ljd.henderson@ntlworld.com HISAR

Cardiff University

Humanities Building

Colum Drive

Cardiff CF10 3EU 